\title{
Effects of Heat Treatments on the Thermoluminescence and Optically Stimulated Luminescence of Nanostructured Aluminate Doped with Rare-Earth and Semi-Metal Chemical Element
}

Sonia Hatsue Tatumi, Alexandre Ventieri, José Francisco Sousa Bitencourt, Katia Alessandra Gonçalves, Juan Carlos Ramirez Mittani, René Rojas Rocca and Shiva do Valle Camargo

Additional information is available at the end of the chapter

http://dx.doi.org/10.5772/51414

\section{Introduction}

Ionizing radiation dosimetry plays a very important role in several fields, useful in the ordinary life, such as radiotherapy, nuclear medicine diagnosis, nuclear medicine, radioisotope power systems, earth science, geological and archaeological dating methods, etc.

The phenomenon of Thermoluminescence (TL) has been known since 1663, when Robert Boyle notified the "Royal Society" in London, which observed the emission of light by a diamond when it was heated in the dark [1]. Afterwards, a large number of scientists began to work with TL; as did Henri Becquerel, whose work described IR measurements spectra [2] and the effect of TL, too. Marie Curie, in 1904, noted that the TL properties of the crystals could be restored by exposing them to radiation from the radio element mentioned in her doctoral thesis. In the middle of the 1930's and 1940's, Urbach performed experimental and theoretical work with TL [1] and in 1945 Randall and Wilkins developed a first theoretical model [3] of thermoluminescent emission kinetics.

The use of thermoluminescence in dosimetry date from 1940, when the number of people working on places with radiation sources such as hospitals, nuclear reactors etc. exposed to ionizing radiations ( $\gamma$-rays, $X$ rays, $\alpha$ and $\beta$-particles, UVA and UVB) increased and efforts to develop new types of dosimeters began [4]. Among the pioneers of TLD we have Daniels, 
1953, with LiF, Bjarngard, 1967 with $\mathrm{CaSO}_{4}$ and Ginther and Kirk (1957) with $\mathrm{CaF}_{2}$. After these works search in other materials such as natural fluorides or synthetic as, $\mathrm{LiBO}_{3}: \mathrm{Mn}$, $\mathrm{CaF}_{2}: \mathrm{Dy}, \mathrm{CaSO}_{4}$ and $\mathrm{MgSiO}_{4}: \mathrm{Tb}$. They usually obtained as monocrystalline samples Czochralski, Bridgmann, etc.

However, Cameron, 1961, with their research on the application of LiF: Mg and Ti obtained the first thermoluminescence dosimeter (TLD-100) [5], which is still one of most popular TLD phosphor, due to tissue equivalent $Z_{\text {eff }}=8.04$, which is an important characteristic for personal dosimetry. Akselrod et al., 1990 [6] carried out studies on TL properties of carbon doped $\mathrm{Al}_{2} \mathrm{O}_{3}$ (TLD-500), a very sensitive material to radiation exposure, showing few TL peaks, with dose interval of detection between $0.05 \mu$ to $10 \mathrm{~Gy}$ and fading rate of $3 \%$ by year (when kept in the dark). This high sensitivity of the material is attributed to oxygen vacancies created during the crystal growth procedure; the electrons can be trapped at these vacancies creating $\mathrm{F}^{-}$and $\mathrm{F}^{+}$centers, which act as recombination centers yielding a bright emission.

In order to increase the luminescence emission response with dose of some thermoluminescence dosimeters (TLD), heat treatments procedures were frequently performed. Halperin et al., 1959, [7] noted that the thermal treatment enhanced the intensity of various TL glow peaks of $\mathrm{NaCl}$ by factors of a few thousands; on prolonged heat treatment. They observed that the intensity of TL peaks locate above RT decreased, while those at lower temperatures continued to grow even after 80 hours of heat treatment at 550 ${ }^{\circ} \mathrm{C}$. Mehendru, 1970 [8], studied the effects of heat treatment on the TL response of pure $\mathrm{KCl}$; they associated the peaks at 95,135 , and $190^{\circ} \mathrm{C}$ with the $\mathrm{F}$ centers, these last created due to the background divalent cation impurities, and with the first- and the second-stage F centers, respectively. Kitis et al., 1990 [9], studied the sensitization of LiF:Mg, $\mathrm{Ti}$ as a function of irradiation at elevated temperatures, pre-irradiation annealing, and post irradiation annealing between $150-400{ }^{\circ} \mathrm{C}$; the results showed that the first and third conditions cause an enhancement of the sensitivity; after more two works about preheating and high temperature annealing on TL glow curves of LiF:Mg, Ti [10] and in LiF TLD100 [11] were published. Holgate, 1994, [12] investigated TL and radioluminescence (RL) spectra of calcium fluoride samples doped with neodymium and variations of spectra with $\mathrm{Nd}$ concentrations and thermal treatments were observed. Nowadays, it is possible to find oxides, sulfates, sulfides and alkali haloids doped with rare-earths and transition metals as commercial dosimeters.

The optically stimulated luminescence (OSL) was pioneered used to determine environmental radiation dose received by geological samples [13]. However, the idea of using OSL dosimetry was first suggested in 1956 [14]. The first experience was made using $\mathrm{MgS}, \mathrm{CaS}, \mathrm{SrS}$ and SrSe phosphors doped with different rare-earths $[15,16]$. Nanto et al., 1993 [17], investigated the OSL properties of single crystals of $\mathrm{KCl}: \mathrm{Eu}$; after, Akselrod et al. 1998 [18], proposed the use of $\mathrm{Al}_{2} \mathrm{O}_{3}: \mathrm{C}$ for OSL dosimetry, because the high sensitivity of the crystal to visible light. At the present time, the crystal is the principal OSL dosimeter [19-22]. Currently, there are various materials proposed for OSL dosimetry as KBr:Eu [23,24], 
$\mathrm{LiAlO}_{2}: \mathrm{Tb}, \mathrm{Li}_{2} \mathrm{Al}_{2} \mathrm{O}_{4}: \mathrm{Tb}, \mathrm{Mg}_{2} \mathrm{SiO}_{4}: \mathrm{Tb}, \mathrm{Mg}_{2} \mathrm{SiO}_{4}: \mathrm{Tb}$, $\mathrm{Co} \mathrm{CaSiO}_{3}: \mathrm{Tb}$ [25]. Some morphological studies was introduced in the science of OSL materials, using high-resolution microscope (TEM) coupled to punctual electron diffraction analysis in nanoscale, showed that dopants formed nanocrystalline structure located at surface of the matrix elements as $\mathrm{Al}_{2} \mathrm{O}_{3}: \mathrm{Mg}$, $\mathrm{Yb}: \mathrm{Er}, \mathrm{Nd}$ and $\mathrm{KAlSi}_{3} \mathrm{O}: \mathrm{Mn}[26-30]$.

Nowadays, luminescent dosimetry materials can be used in personal dosimetry, radiotherapy, nuclear medicine and diagnostic and environmental dosimetry they are widely used due to high sensitivity, linear response to the dose, the response is independent with radiation energy (within a certain range), their reusability, etc.

The aim of this chapter is to present a very comprehensive research about new materials consisting in aluminate crystals doped with rare-earths, for radiation dosimetry using TL and OSL.

Some features on fabrication of aluminates dosimeters will be shown relating the luminescence response according to the relative concentration of several rare-earths and transition metals. A study in nanoscale effects, size, shape and surface morphology using TEM, SEM, EDS and electron diffraction measurements will be shown too. The physicochemical properties of the doped materials are strongly related to the fabrication process as well the experimental parameters as temperature of thermal treatments, calcination time, heating rates, etc.

As materials science has developed down to nanoscale, the exceptional properties of nanoscaled rare-earth materials are only now being recognized and performed intentionally.

\section{Experimental part}

Polycrystalline powder samples of $\alpha-\mathrm{Al}_{2} \mathrm{O}_{3}: \mathrm{Er}, \mathrm{Yb} ; \mathrm{Mg}$; $\mathrm{Tb}$ and $\mathrm{Nd}$ were obtained by sol-gel and Pechini process. In the sol-gel procedure stoichiometric amounts of tri-sec-butoxide of aluminum was dissolved in distilled water and hydrochloric acid. The dopants $\mathrm{Er}, \mathrm{Yb}, \mathrm{Nd}$ and $\mathrm{Tb}$ oxides were added during the sol stage, with different concentrations. Some portions of the resulting powder were calcinated at different temperature from 1200 to $1600{ }^{\circ} \mathrm{C}$. Experimental parameters of the calcination process, as heating and cooling rates and set point values were varied, in order to verify the effect on the luminescence response.

Pechini is a chemical routine that produces, at the end of the stage, an organic polymer with metallic ions, which will be responsible for the formation of the desired material. The polymer is obtained after low temperature reaction among ethylene glycol, citric acid and aluminum nitrate. Once the polymer is ready, a number of heat treatments are carried out in order to (1) collapse the polymeric structure and allow the gradual oxidation reaction of the metallic ions with atmospheric oxygen, and (2) obtain the desired structure of the material. This technique is known to obtain uniform composition and controlled grain size distribution, due to the slow oxidation reaction and the viscosity of the polymer, which avoid precipitation. 
The morphological characteristics of the samples were analyzed using a Philips CM200 TEM equipped with EDS operating at $160 \mathrm{keV}$, some $\mathrm{Cu}$ contamination from the sample holder can be observed in the all the EDS results, the samples were located at $400 \mathrm{~mm}$ from the source. The X-ray powder diffractions were recorded with the MiniFlex II model diffractometer of Rigaku Corporation.

TL and OSL measurements were performed in an oxygen-free nitrogen atmosphere using Daybreak Nuclear and Medical Systems Inc, model 1100-series TL/OSL reader and RISØ TL/OSL reader Model DA - 20.

TL was detected using the BG-39 $(340-610 \mathrm{~nm})$ optical filter and heating rate of $10{ }^{\circ} \mathrm{C} / \mathrm{s}$. OSL measurements were made using an array of blue $(470 \mathrm{~nm})$ LEDs for sample stimulation and detected in the UV with a Schott U-340 optical filter.

The irradiations were performed at RT in a ${ }^{60} \mathrm{Co}$ source with dose rate of $28.7 \mathrm{~Gy} / \mathrm{h}$ and with a beta source $\left({ }^{90} \mathrm{Sr} /{ }^{90} \mathrm{Y}\right)$ coupled to the RIS $\varnothing \mathrm{TL} / \mathrm{OSL}$ reader, with dose rate of $0.08 \mathrm{~Gy} / \mathrm{s}$.

\section{Results and discussion}

\subsection{XRD}

Figure 1a shows the XRD of pure alumina produced by sol -gel without any dopants. A very well agreement with standard $\alpha-\mathrm{Al}_{2} \mathrm{O}_{3}$ pattern is observed (Figure1a). On the other hand, doped samples show additional peaks related with new structures formed by the dopants and the alumina matrix, for example, in the case of $\mathrm{Tb}$ doped samples it was verified the $\mathrm{Tb}_{3} \mathrm{Al}_{5} \mathrm{O}_{12}$ crystalline structure (Figure $1 \mathrm{~b}$ ), and for $\mathrm{Nd}$ doped sample the $\mathrm{AlNd}$ structure (Figure 1c).

Sample doped with $\mathrm{Er}$ and $\mathrm{Yb}$ and calcinated at $1200{ }^{\circ} \mathrm{C}$ supplied a broad background, related to amorphous phase, and many other peaks associated to $\mathrm{Yb}_{2} \mathrm{O}_{3}, \mathrm{Er}_{2} \mathrm{O}_{3}$ and $\mathrm{Yb}_{3} \mathrm{Al}_{5} \mathrm{O}_{12}$. For the sample calcinated at $1600^{\circ} \mathrm{C}$ it was not observed the background, but the peaks of $\mathrm{Yb}_{2} \mathrm{O}_{3}, \mathrm{Er}_{2} \mathrm{O}_{3}$ with predominance of the $\mathrm{Yb}_{3} \mathrm{Al}_{5} \mathrm{O}_{12}$ (Figure 1d and e) were noted.

Figure 2 shows XRD patterns of alumina powder obtained by Pechini process. Applying crescent calcinations temperatures, we can obtain alumina in gamma and alpha phase (Figure $2 \mathrm{a}$ and $2 \mathrm{~b}$ ). The $\mathrm{Mg}$ addition promoted the formations of $\mathrm{MgAl}_{2} \mathrm{O}_{4}$ crystals (Figure 2c). When the doped sample is heated up to $1100{ }^{\circ} \mathrm{C}$ (Figure $2 \mathrm{~d}$ ), most of the material is converted to $\alpha-\mathrm{Al}_{2} \mathrm{O}_{3}$, except for a few low intensity peaks related to the occurrence of magnesium spinel $\left(\mathrm{MgAl}_{2} \mathrm{O}_{4}\right)$. This observation will be corroborated in the next section through TEM images.

\subsection{Thermoluminescence}

TL glow curves of samples obtained with different calcinations temperatures, and detected in UV and VIS regions are shown in Figure $3 a$ and $3 b$, respectively. It can be seen that calcinations at $1600{ }^{\circ} \mathrm{C}$ favored the increase of $190{ }^{\circ} \mathrm{C}$ TL dosimetric peak and diminution on 
intensity of high temperature peak simultaneously. The TL intensity in VIS region is higher than those found in the UV one.

(a)

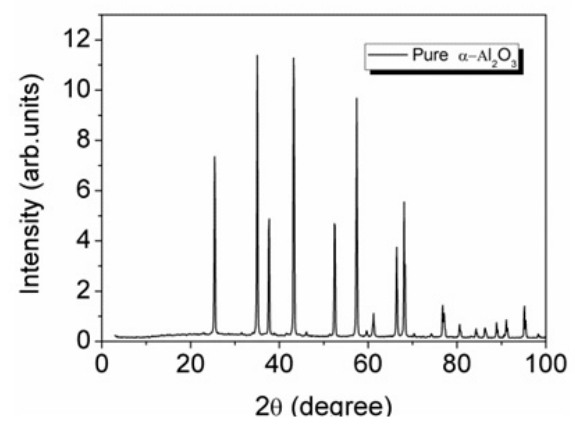

(c)

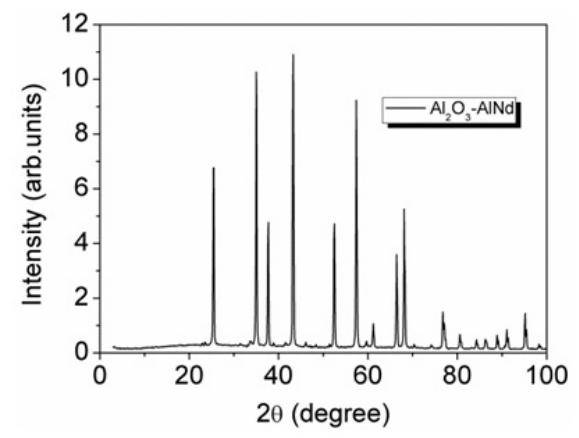

(b)

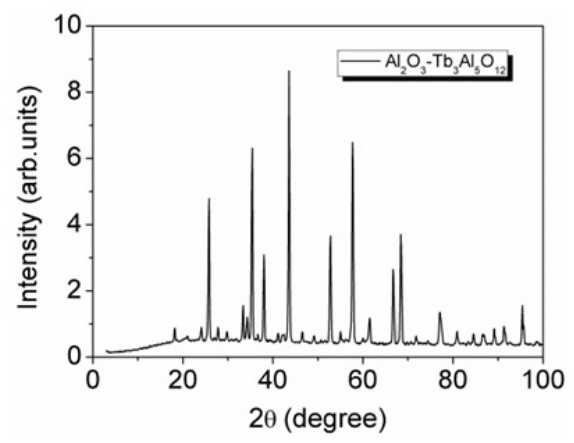

$(d)$

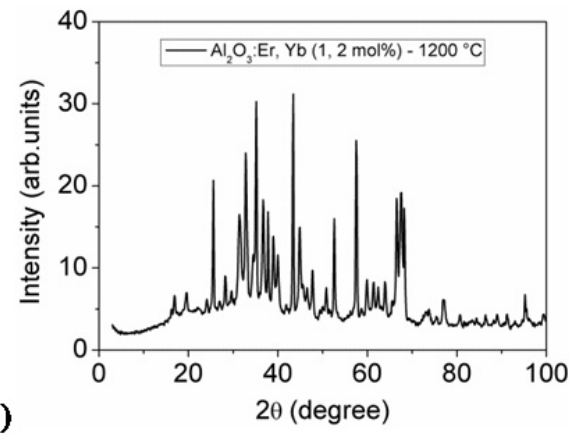

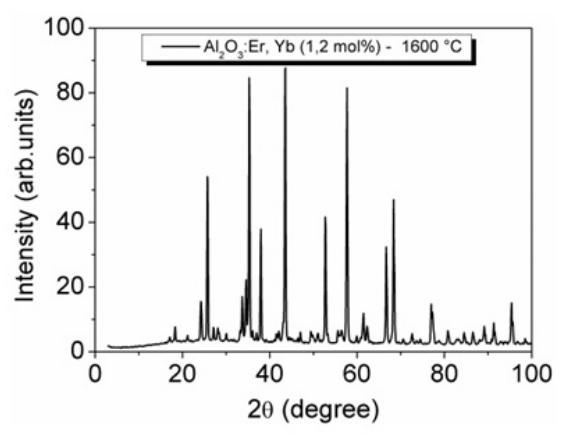

Figure 1. XRD pattern of the $\alpha-\mathrm{Al}_{2} \mathrm{O}_{3}$ samples, a) undoped sample, b) doped with $\mathrm{Tb}, \mathrm{c}$ ) doped with $\mathrm{Nd}, \mathrm{d}) \mathrm{Er}$ and $\mathrm{Yb}(1$ and $2 \mathrm{~mol} \%)$ doped and calcinated at $1200{ }^{\circ} \mathrm{C}$ and (e) Er and $\mathrm{Yb}(1$ and $2 \mathrm{~mol} \%)$ and calcinated at $1600^{\circ} \mathrm{C}$. 
(a)

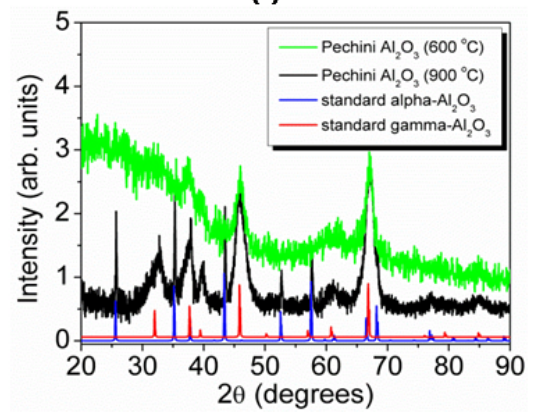

(c)

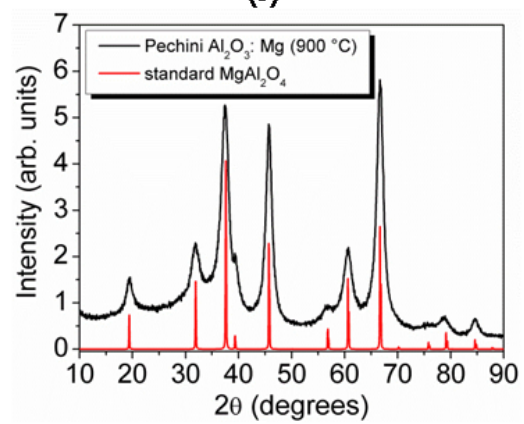

(b)

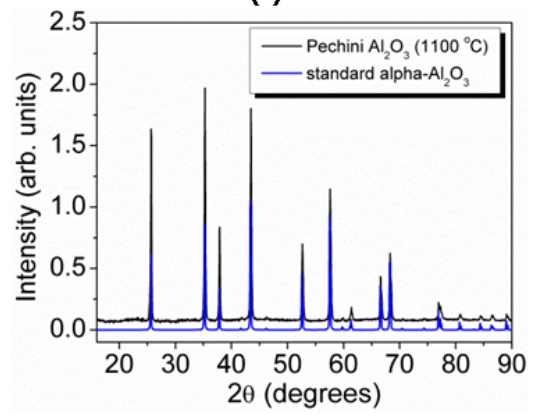

(d)

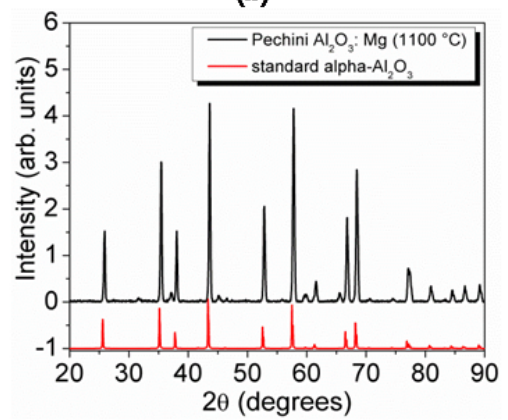

Figure 2. XRD patterns from $\mathrm{Al}_{2} \mathrm{O}_{3}$ samples obtained from Pechini routine. a) shows undoped samples annealed at 600 and $900{ }^{\circ} \mathrm{C}$ and standard patterns found for $\gamma-\mathrm{Al}_{2} \mathrm{O}_{3}$ and $\alpha-\mathrm{Al}_{2} \mathrm{O}_{3}$. b) shows XRD from undoped sample annealed at $1100{ }^{\circ} \mathrm{C}$ and the standard $\alpha-\mathrm{Al}_{2} \mathrm{O}_{3}$. Magnesium doped sample annealed at $900{ }^{\circ} \mathrm{C}$ is shown in (c) with the standard pattern of magnesium spinel $\left(\mathrm{MgAl}_{2} \mathrm{O}_{4}\right)$. After annealing at $1100{ }^{\circ} \mathrm{C}$, magnesium doped sample produced the XRD shown in (d).

Figure $3 \mathrm{c}$ and $3 \mathrm{~d}$ show results of TL responses in UV and VIS regions with set point times varying of $30 \mathrm{~min}, 1,2,4$ and $8 \mathrm{~h}$. In the UV region, the thermal treatment of $4 \mathrm{~h}$ promoted a high increment of the $190{ }^{\circ} \mathrm{C}$ peak while in VIS region, the time was of $8 \mathrm{~h}$. It is known from literature that the emission mechanism of these two luminescence regions is different. In the case of $\mathrm{UV}$ emission, the responsible is the $\mathrm{F}^{+}$center according the mechanism:

$$
\mathrm{F}+\mathrm{h}^{+} \rightarrow \mathrm{F}^{+^{*}} \rightarrow \mathrm{F}^{+}+\mathrm{h} v_{325 \mathrm{~nm}} \text { (stimulation process, TL/OSL) }
$$

Where the recombination of the $\mathrm{F}$ center with a hole $\left(\mathrm{h}^{+}\right)$generates an excited $\mathrm{F}^{+^{*}}$, which decays into the ground state (transition $1 \mathrm{~B} \rightarrow 1 \mathrm{~A}$ ) emitting a photon at $325 \mathrm{~nm}$. Therefore, the calcinations at $1600{ }^{\circ} \mathrm{C}$ stimulated an increase of $\mathrm{F}$ centers concentration.

In the other case of VIS emission, it is believed that the luminescence occurs as follows [31, 32]:

$$
\begin{gathered}
\mathrm{F} \rightarrow \mathrm{F}^{+}+\mathrm{e}^{-} \text {(irradiation process) } \\
\mathrm{F}^{+}+\mathrm{e}^{-} \rightarrow \mathrm{F}^{*} \rightarrow \mathrm{F}+\mathrm{h} v_{410-420 \mathrm{~nm}} \text { (heating process, } \mathrm{TL} \text { ) }
\end{gathered}
$$


(a)

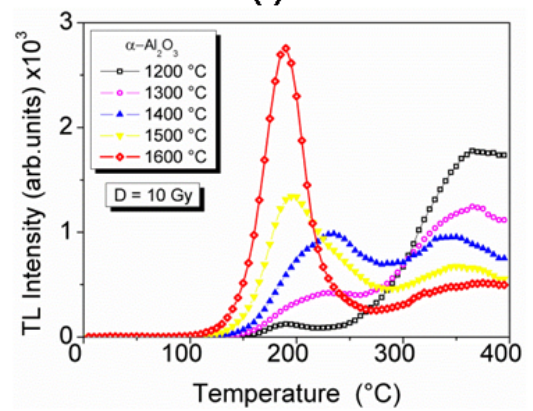

(c)

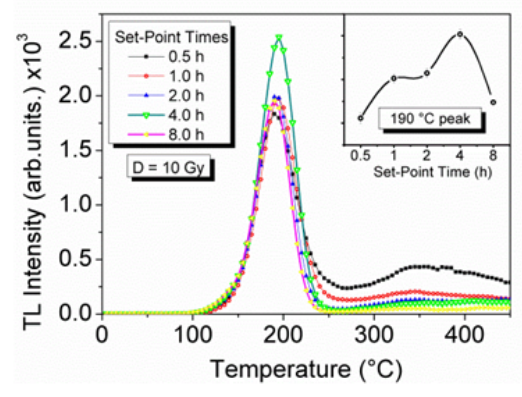

(b)

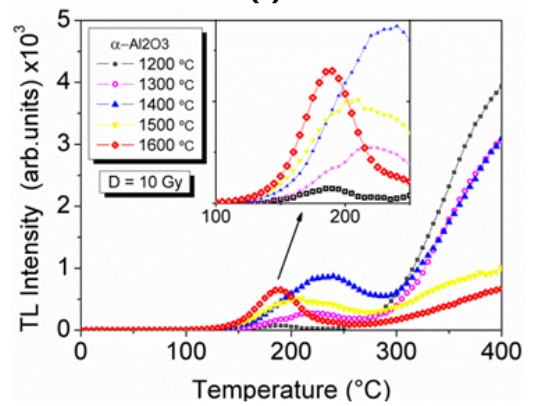

(d)

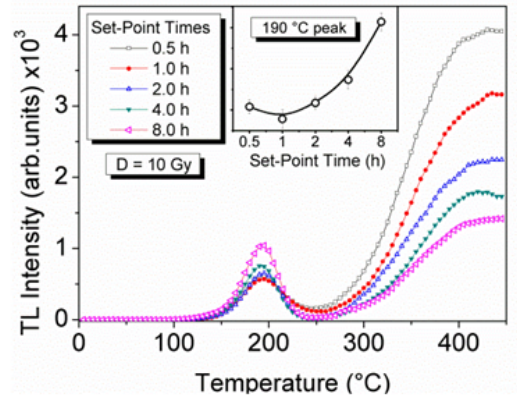

Figure 3. TL glow curves of pure alumina samples obtained by sol-gel process, study of effects of calcination temperatures and time on the TL response. a) UV emission with different calcinations temperatures; b) VIS emission with different calcinations temperatures; c) UV emission with different set-point times and d) VIS emission with different set-point times.

Where $\mathrm{F}$ center loses an electron after absorption of high energy radiation and become $\mathrm{F}^{+}$ center. On thermal stimulation, the recombination of the electron and the $\mathrm{F}^{+}$center produces an excited $\mathrm{F}$ center $\left(\mathrm{F}^{*}\right)$, which decays into its ground state (3P transition state $\rightarrow 3 \mathrm{~S}$ ) with the emission of photons at $410-420 \mathrm{~nm}$.

Therefore, following our results the long set point time $(\sim 8 \mathrm{~h})$ favored the electron traps formations, and in the case of UV emission we have the great rate of formation of hole traps after 4 hours of calcinations.

Figure 4 shows TL glow curves of pure alumina obtained with different heating and cooling rates. In all cases the slow rate of $3{ }^{\circ} \mathrm{C} / \mathrm{min}$ supplied the best result, confirming that longer calcinations time can promote a better diffusion of the defects and ions and also eliminates the internal tension forces in the crystalline lattice, which can homogenize the crystal.

TL glow curves of the samples doped with $\mathrm{Er}$ and $\mathrm{Yb}$ are shown in the Figure $5 \mathrm{a}$ and $5 \mathrm{~b}$. Samples calcinated at $1200{ }^{\circ} \mathrm{C}$ supplied one peak at high temperature (Figure 5a), which did not increase proportionally to the dose and another peak at low temperature region with very low intensity. After calcinations at $1600{ }^{\circ} \mathrm{C}$, two prominent peaks at $224{ }^{\circ} \mathrm{C}$ and $442{ }^{\circ} \mathrm{C}$ 
were observed (Figure 5b). For the sample doped with $\operatorname{Er}(1 \mathrm{~mol} \%)$ and $\mathrm{Yb}(2 \mathrm{~mol} \%)$, the peak temperature changed to $203^{\circ} \mathrm{C}$ and an increment about 1.4 time in the TL intensity was observed. In all the samples, the TL response of the high temperature peak is not proportional to the dose. For samples doped with $\mathrm{Tb}(2.5 \mathrm{~mol} \%)$ and $\mathrm{Nd}(2.5 \mathrm{~mol} \%)$ an increased in UV intensity of the $190{ }^{\circ} \mathrm{C}$ peak was also noted, the first one increased 3.5 times and for $\mathrm{Nd}$ was 2.5 times, when compared to undoped one (Figure $5 \mathrm{c}$ ).

(a)

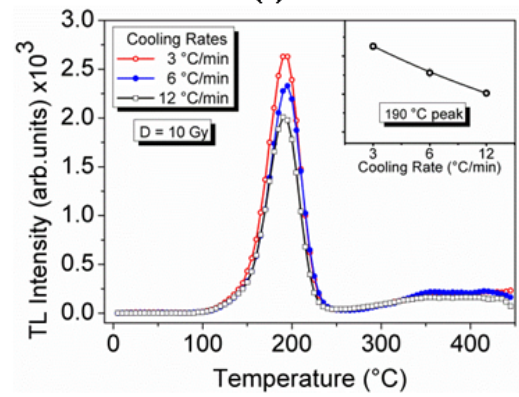

(c)

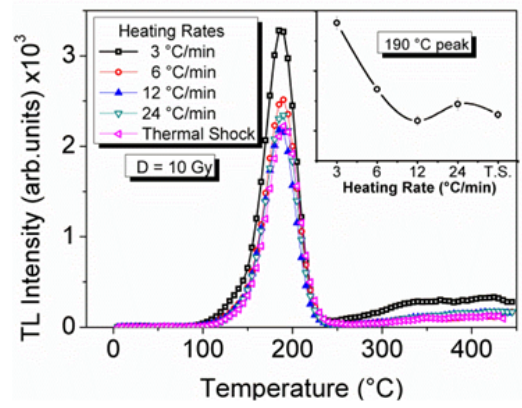

(b)

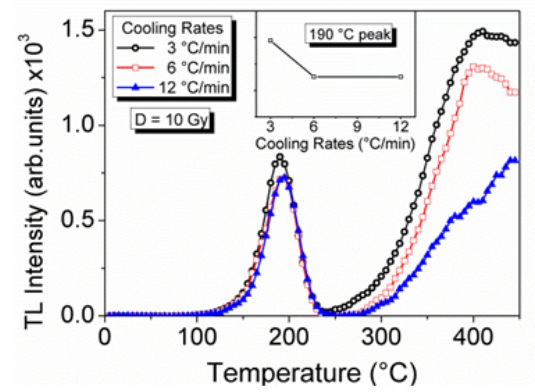

(d)

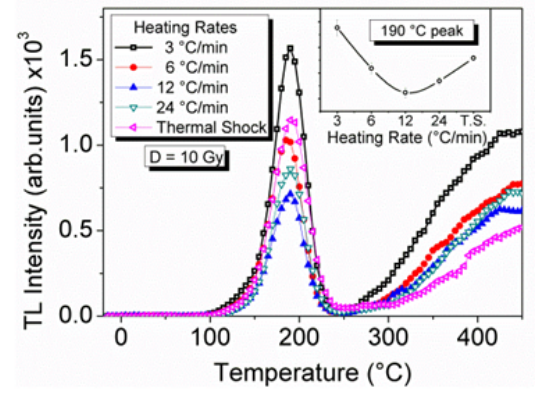

Figure 4. TL glow curve of pure alumina samples obtained by sol-gel process a) UV emission with different heating rates b) VIS emission with different heating rates; c) UV emission with different cooling rates d) VIS emission with

Figure 6 shows TL glow curves of pure and Mg doped samples obtained by Pechini process, the curves are slightly different from those obtained by sol-gel. High intensities for $190{ }^{\circ} \mathrm{C}$ TL peak from pure samples were obtained at $1100{ }^{\circ} \mathrm{C}$ for VIS region (Figure 6a) and at 1350 ${ }^{\circ} \mathrm{C}$ for UV one (Figure $6 \mathrm{~b}$ ). On sample doped with $\mathrm{Mg}$ high intensities were detected in both cases UV and VIS with calcinations at $1600{ }^{\circ} \mathrm{C}$, the same value found in sol-gel samples.

Figure 6 shows TL glow curves for samples produced via Pechini method. As the calcination temperature increases, different observations can be made, depending on the composition and the measurement spectra. In Figure 6a, showing TL emission of undoped sample in the visible region, all the peaks intensities decrease for higher temperatures, but mainly low temperature $\left(90^{\circ} \mathrm{C}\right)$ and high temperature $\left(410^{\circ} \mathrm{C}\right)$ peaks. In this case, the best sample would be the one calcinated at $1350^{\circ} \mathrm{C}$, due to its high intensity and low competition among 
the trapping centers (more stable TL signal). High temperature treatments can destroy as well as create trapping and recombination centers, and that explains why some TL peaks may disappear, whilst others may rise or increase.
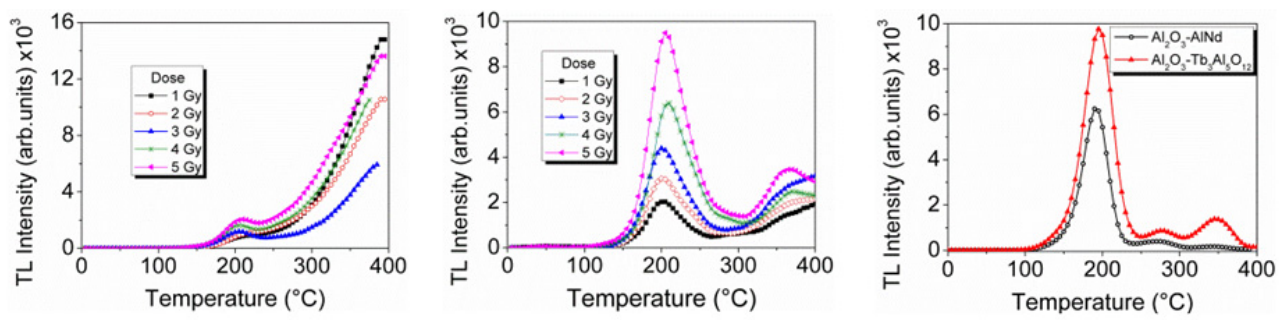

Figure 5. TL glow curve of $\alpha-\mathrm{Al}_{2} \mathrm{O}_{3}$ obtained by sol gel: a) doped with $\mathrm{Er}, \mathrm{Yb}(1,2 \mathrm{~mol} \%)$, calcinated at $1200{ }^{\circ} \mathrm{C}$ and irradiated with $\gamma$-rays, b) doped with $\mathrm{Er}, \mathrm{Yb}(1,2 \mathrm{~mol} \%)$, calcinated at $1600{ }^{\circ} \mathrm{C}$ and irradiated with $\gamma$-rays and c) TL glow curve UV emission of sample doped with $\mathrm{Nd}(2.5 \%)$ (black open circle) and $\mathrm{Tb}\left(2.5 \%\right.$ ) (red triangle), both calcinated at $1600^{\circ} \mathrm{C}$ and irradiated with $10 \mathrm{~Gy}$.

(a)

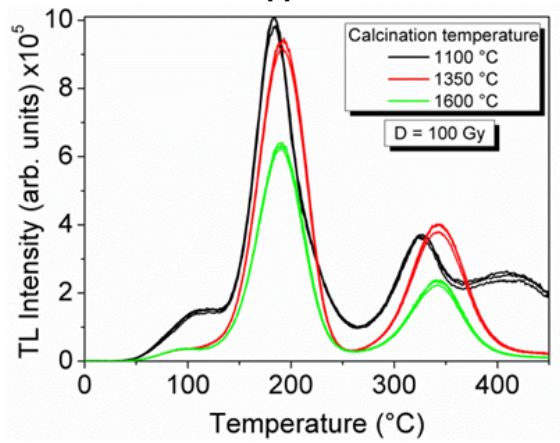

(c)

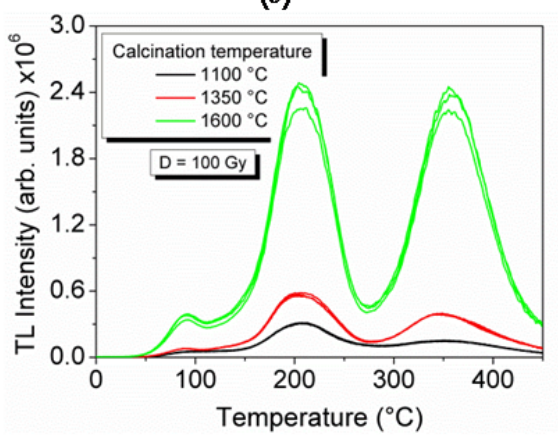

(b)

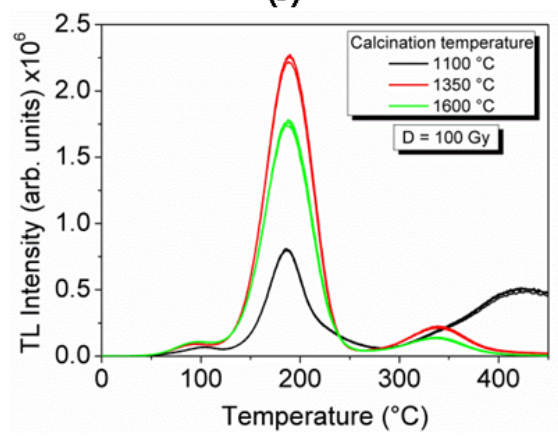

(d)

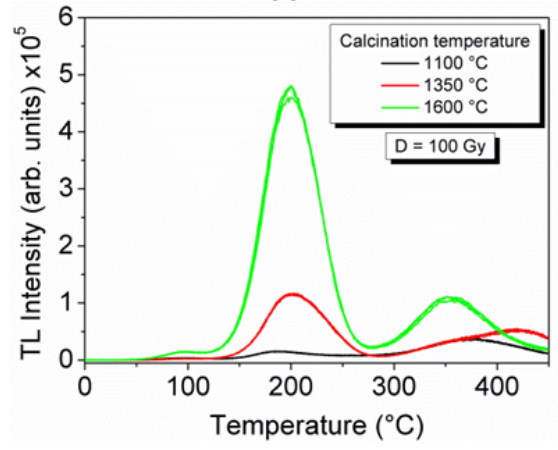

Figure 6. $\mathrm{TL}$ glow curves from $\mathrm{Al}_{2} \mathrm{O}_{3}(\mathrm{a}$ and $\mathrm{b})$ and $\mathrm{Al}_{2} \mathrm{O}_{3}: \mathrm{Mg}$ (c and d) samples obtained from Pechini routine and annealed at 1100,1350 and $1600{ }^{\circ} \mathrm{C}$. Measurements were taken in both visible (a and c) and $\mathrm{UV}(\mathrm{b}$ and $\mathrm{d})$ spectra. 
Figure $6 \mathrm{~b}$ is the TL emission of undoped sample in the UV region, which indicates that high temperature peaks tend to fade when the sample is calcinated at higher temperatures. Once again, the sample calcinated at $1350{ }^{\circ} \mathrm{C}$ showed the best glow curve. For the undoped sample, calcination at $1600{ }^{\circ} \mathrm{C}$ seems to increase the competition, which decreases the overall intensity. It is not likely that the high temperature is damaging the material, since the melting point is still too far away (around $2050{ }^{\circ} \mathrm{C}$ ). Also, the high temperature may be causing the crystallites to grow, decreasing the surface area exposed to the incoming radiation, thus changing the trapping dynamics at some level.

The incorporation of magnesium atoms in the crystalline lattice made a great deal on the TL response of the samples. In the first place, both visible and UV emissions (Figures $6 \mathrm{c}$ and $6 \mathrm{~d}$, respectively) increased with the increasing of the calcination temperature, which was not observed for undoped samples. Secondly, the high temperature peak $\left(355^{\circ} \mathrm{C}\right)$ of the visible emission had its intensity increased by a factor of 3; a minor difference on the relation between the main dosimetric peak and the high temperature one was also observed for the UV emission.

It is important to observe that only samples calcinated above $1100{ }^{\circ} \mathrm{C}$ exhibited some appreciable TL emission; this means that $\alpha-\mathrm{Al}_{2} \mathrm{O}_{3}$ acts as a better ionizing radiation sensor than other phases $\left(\delta\right.$ and $\gamma$ ). For samples calcinated below that temperature $\left(600\right.$ and $\left.900{ }^{\circ} \mathrm{C}\right)$, most of the trapping and recombination centers may not yet be active.

One reason for the high luminescence of $\alpha-\mathrm{Al}_{2} \mathrm{O}_{3}: \mathrm{C}$ comes from the theory of point defects. It is known that the synthesis of carbon doped alumina is done in a highly reductive atmosphere of carbon ions, resulting into a great production of oxygen vacancies in the crystalline lattice. If these vacancies are occupied by two electrons we have the formation of the neutral F center. Otherwise, if the vacancy is occupied by only one electron, we have the formation of $\mathrm{F}^{+}$center. In the latter situation, the presence of charge compensation is demanded for the $\mathrm{F}^{+}$center formation; in the case of the $\alpha-\mathrm{Al}_{2} \mathrm{O}_{3}: \mathrm{C}$ it is $\mathrm{C}^{2+}$ impurity, which replaces $\mathrm{Al}^{3+}$ ion in the crystalline lattice. In our case we suppose that the $\mathrm{Mg}$ is acting as $\mathrm{C}$ impurity.

\subsection{Thermoluminescence spectra}

TL spectra of pure and doped with $\mathrm{Tb}, \mathrm{Er}-\mathrm{Yb}$, and $\mathrm{Nd}$ alumina are shown in Figures 7a) to $7 \mathrm{~d}$ ) respectively. On visible region from 360 to $600 \mathrm{~nm}$ luminescence bands due to rare-earth elements are observed on doped samples. However all the samples pure and doped showed an intense luminescence band between 650 and $800 \mathrm{~nm}$ not identified yet in the literature. However, from fluorescence results, this band is usually associated to $\mathrm{Cr}^{3+}$ impurity incorporated in raw materials used for alumina production [33].

When the dopant are incorporated, other bands are detected related to the rare-earth elements (Figure 7b, 7c, and 7d). The Tb doped sample shows, in addition for the first at 694 $\mathrm{nm}$, another broad band at $428 \mathrm{~nm}$, with $187 \mathrm{~nm}$ of width, due to the transitions of $\mathrm{Tb}^{3+}$. The results are in agreements with the transitions of ${ }^{5} \mathrm{D}_{3}$ and ${ }^{5} \mathrm{D}_{4} \rightarrow{ }^{7} \mathrm{~F}_{\mathrm{j}}(\mathrm{j}=1-6)$. 
(a)

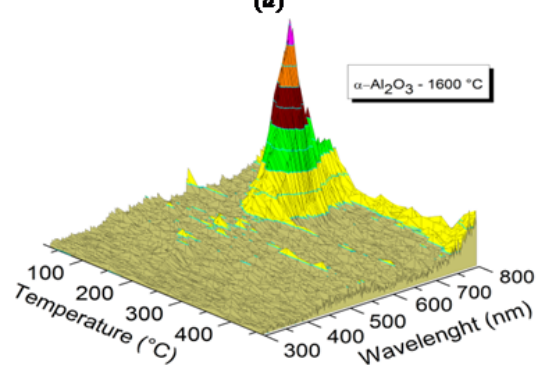

(c)

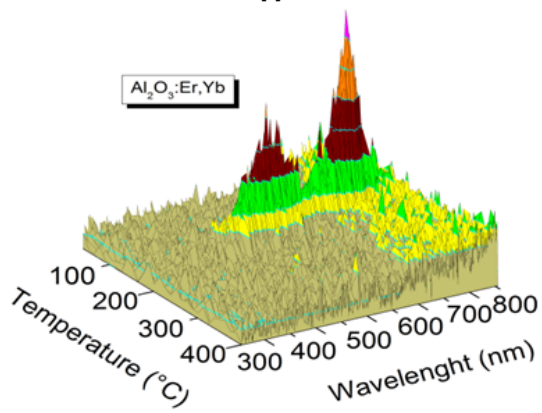

(b)

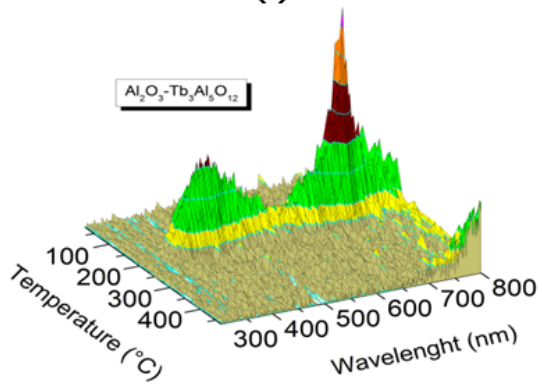

(d)

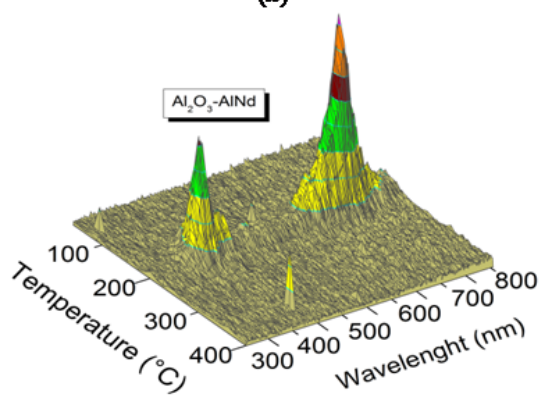

Figure 7. TL spectra of Alumina, a) undoped sample, b) Tb doped sample, c) Er and $\mathrm{Yb}$ doped sample, d) $\mathrm{Nd}$ doped sample.

In the case of $\mathrm{Al}_{2} \mathrm{O}_{3}: \mathrm{Er}: \mathrm{Yb}$ sample, the band is centered at $528 \mathrm{~nm}(448-589 \mathrm{~nm})$ and the emission mechanism can be related to these rare-earth elements. It is well known that $\mathrm{Er}^{3+}$ has high efficiency for the infrared to visible light conversion and cooperative sensitization properties. The ${ }^{4} \mathrm{I}_{11 / 2}\left(\mathrm{Er}^{3+}\right)$ level and ${ }^{2} \mathrm{~F}_{5 / 2}\left(\mathrm{Yb}^{3+}\right)$ state are very closely matched in energy, thus the exposition from the 0.9 to $1.1 \mu \mathrm{m}$ range will excite both $\mathrm{Er}^{3+}$ and $\mathrm{Yb}^{3+}$ ions. The visible emission can occurs because the $\mathrm{Yb}^{3+}$ transfers the excitation energy to $\mathrm{Er}^{3+}$ and the final state of this process is the population of the ${ }^{4} \mathrm{~F}_{7 / 2}$ state and nonradiative relaxation to the ${ }^{4} \mathrm{~S}_{3 / 2}$ level, from which green photon $(547 \mathrm{~nm})$ is emitted. The excitation routes for red emission at $660 \mathrm{~nm}$ are not clear yet; in this case the $\mathrm{Yb}^{3+}$ transfer energy to $\mathrm{Er}^{3+}$ and the red emission occurs in the ${ }^{4} \mathrm{~F}_{9 / 2} \rightarrow{ }^{4} \mathrm{I}_{15 / 2}$ transition [34].

For $\mathrm{Nd}$ doped sample, it was noted emission at $396 \mathrm{~nm}(364-460 \mathrm{~nm})$. It is known that $\mathrm{Nd}^{3+}$ can emit in UV region and the possible transitions related to these emissions are: ${ }_{4} \mathrm{D}^{5 / 2}{ }_{4} \mathrm{D}^{3 / 2}$ ${ }_{4} \mathrm{P}^{3 / 2} \rightarrow{ }_{4} \mathrm{I}^{9 / 2} ;{ }_{4} \mathrm{D}^{5 / 2}{ }^{4} \mathrm{D}_{3 / 2}{ }^{4} \mathrm{P}_{3 / 2} \rightarrow{ }^{4} \mathrm{I}_{11 / 2}[35]$.

\subsection{Optically stimulated luminescence}

As seen in TL emission curves showed previously, the response of OSL signal also increased for samples calcinated at high temperatures, for both samples obtained by sol-gel (Figure 8a) 
and Pechini process (Figure 8b). Figure 8c and 8d show an example of OSL increment about 3 times, after calcination at $1600{ }^{\circ} \mathrm{C}$.

OSL decays can be fitted by exponential functions [36], depending on the number of the traps involved in the process, for example for two traps we have:

$$
\mathrm{I}_{\mathrm{OSL}}=\mathrm{I}_{1} \exp \left(-\frac{\mathrm{t}}{\tau_{1}}\right)+\mathrm{I}_{2} \exp \left(-\frac{\mathrm{t}}{\tau_{2}}\right)
$$

Where IosL is the total OSL intensity, $\mathrm{I}_{1}$ and $\mathrm{I}_{2}$ are the initial intensities of exponentially decaying from faster and slower components of the shinedown curve; $\tau_{1}$ and $\tau_{2}$ the respective decay constants.

\begin{tabular}{|c|c|c|c|}
\hline $\begin{array}{c}\text { Sample - } \\
\text { Pechini Process } \\
\end{array}$ & $\begin{array}{c}\text { Calcination } \\
\text { temperature }\left({ }^{\circ} \mathrm{C}\right)\end{array}$ & $\begin{array}{c}\tau_{1} \\
\left(\mathrm{~s}^{-1}\right)\end{array}$ & $\begin{array}{c}\tau_{2} \\
\left(\mathrm{~s}^{-1}\right)\end{array}$ \\
\hline $\mathrm{Al}_{2} \mathrm{O}_{3}$ & 1100 & $3.05 \pm 0.03$ & $13.4 \pm 0.3$ \\
\hline $\mathrm{Al}_{2} \mathrm{O}_{3}$ & 1350 & $2.415 \pm 0.005$ & $11.11 \pm 0.04$ \\
\hline $\mathrm{Al}_{2} \mathrm{O}_{3}$ & 1600 & $2.27 \pm 0.05$ & $11.5 \pm 0.2$ \\
\hline $\mathrm{Al}_{2} \mathrm{O}_{3}: \mathrm{Mg}$ & 1100 & $2.49 \pm 0.09$ & $13.8 \pm 0.6$ \\
\hline $\mathrm{Al}_{2} \mathrm{O}_{3}: \mathrm{Mg}$ & 1350 & $2.6 \pm 0.1$ & $12.6 \pm 0.9$ \\
\hline $\mathrm{Al}_{2} \mathrm{O}_{3}: \mathrm{Mg}$ & 1600 & $2.22 \pm 0.05$ & $11.3 \pm 0.3$ \\
\hline \multicolumn{4}{|l|}{$\begin{array}{c}\text { Sample } \\
\text { Sol Gel Process } \\
\end{array}$} \\
\hline $\mathrm{Al}_{2} \mathrm{O}_{3}$ & 1600 & $9.0 \pm 2.0$ & $41 \pm 11$ \\
\hline $\mathrm{Al}_{2} \mathrm{O}_{3}: \mathrm{Yb}: \mathrm{Er}$ & 1600 & $22.5 \pm 1.0$ & $-0-$ \\
\hline $\mathrm{Al}_{2} \mathrm{O}_{3}: \mathrm{Nd}$ & 1600 & $13.3 \pm 0.8$ & $54 \pm 11$ \\
\hline $\mathrm{Al}_{2} \mathrm{O}_{3}: \mathrm{Tb}$ & 1600 & $8.7 \pm 2.2$ & $45 \pm 6.0$ \\
\hline
\end{tabular}

Table 1. Values for decay constants obtained from theoretical fitting of the OSL curves of alumina (equation 4).

Table 1 shows the decay constants obtained for the studied samples. All the OSL decay curves can be fitted by second order exponential function, except for $\mathrm{Er}$ and $\mathrm{Yb}$ doped sample, which followed first order decay. For samples obtained by Pechini process the high temperatures calcinations diminished the constants values, the fast component value for both pure and $\mathrm{Mg}$ doped samples heated at $1600{ }^{\circ} \mathrm{C}$ supplied almost same constants decays. In the case of samples made by sol-gel, the Tb doped sample has constants similar to those determined by pure alumina. However, the incorporation of $\mathrm{Nd}$, Er and $\mathrm{Yb}$ changed the constants values. The OSL curves of the samples obtained by sol-gel supplied greatest decay constants. Yang et al. [37] showed some OSL fitting results of $\alpha-\mathrm{Al}_{2} \mathrm{O}_{3}: \mathrm{C}$ excited by green light and detected in the UV, and they found that $\tau_{1}$ vary from 4.6 to $11.3 \mathrm{~s}^{-1}$ and $\tau_{2}$ from 24.1 to $30.1 \mathrm{~s}^{-1}$. They attributed the variations to different concentrations of $\mathrm{F}$ and $\mathrm{F}^{+}$centers in the sample. Nevertheless, our results indicated that $\tau$ values are constant and do not depend of dose values delivered to the samples, the results for $\tau_{1}$ are similar to those found in the literature, however $\tau_{2}$ are relatively higher. 
(a)

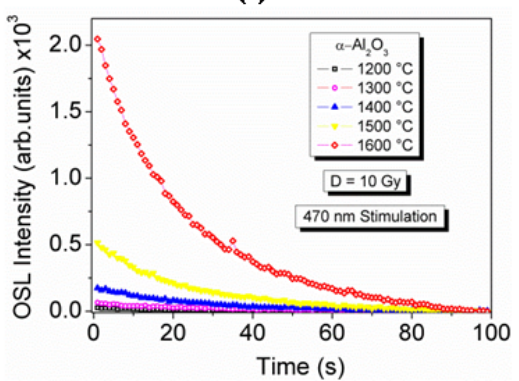

(c)

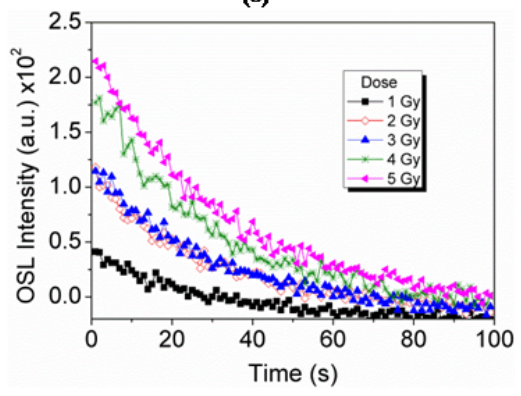

(b)

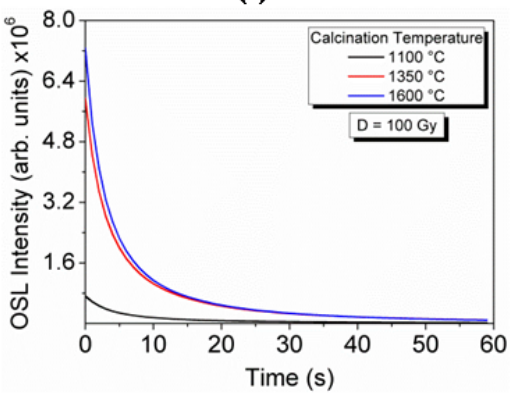

(d)

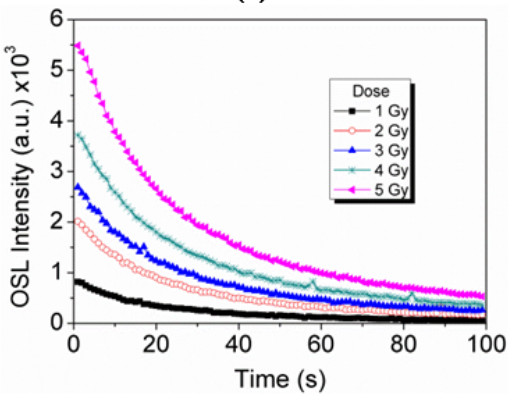

e)

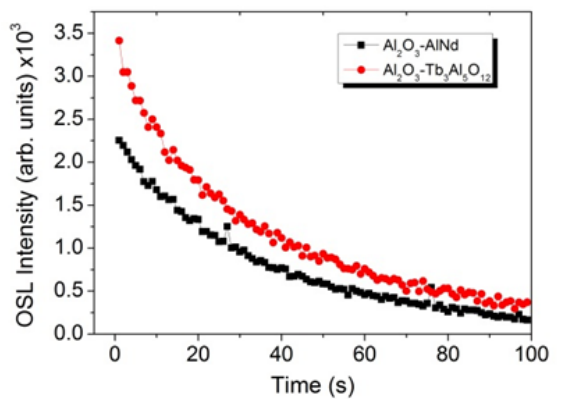

Figure 8. OSL curves of alumina, a) undoped samples obtained by sol-gel with different calcinations temperatures, $b$ ) undoped samples obtained by Pechini process with different calcinations temperatures, c) $\mathrm{Er}, \mathrm{Yb}$ doped samples calcinated at $1200^{\circ} \mathrm{C}$ and irradiated with gamma-radiations, d) $\mathrm{Er}, \mathrm{Yb}$ doped samples calcinated at $1600{ }^{\circ} \mathrm{C}$ and irradiated with gamma-radiations and e) $\mathrm{Nd}$ and $\mathrm{Tb}$ doped samples calcinated at $1600^{\circ} \mathrm{C}$.

\subsection{TEM}

According to TEM images, it was verified that all the doped samples present nanocrystals formations on the surface of alumina grains (Figure 9a). In Tb doped sample, it was verified the presence of $\mathrm{Tb}_{3} \mathrm{Al}_{5} \mathrm{O}_{12}$, the chemical structure was determined by electron diffraction and EDS results (Figure 9b). Nanocrystals of AlNd are easily observed with its well developed 
faces (Figure 10a), in most of the case, the nanocrystals average size is about $200 \mathrm{~nm}$, these aluminates composition was also verified by the EDS (Figure 10b).

a)

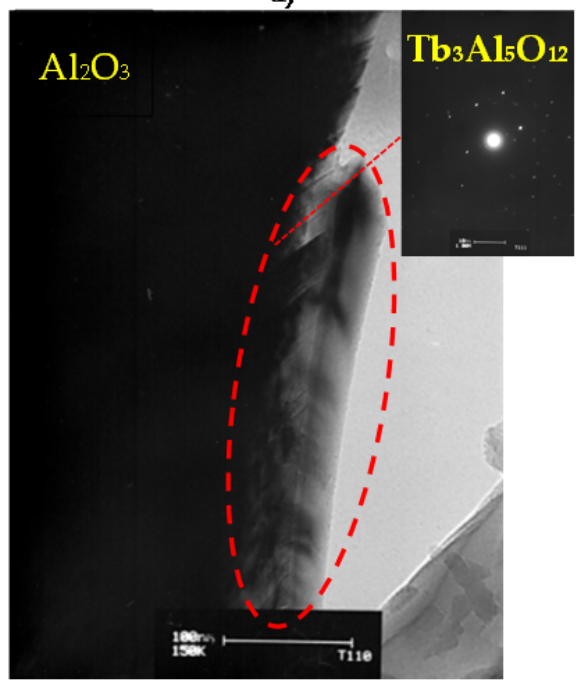

b)

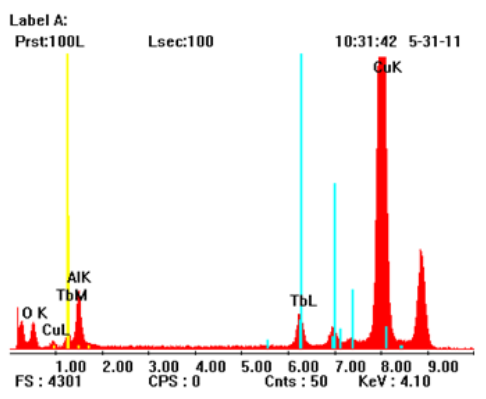

Figure 9. TEM image from $\mathrm{Tb}$ doped $\mathrm{Al}_{2} \mathrm{O}_{3}$ and electron diffraction showing the presence of nanocrystals of $\mathrm{Tb}_{3} \mathrm{Al}_{5} \mathrm{O}_{12}$. b) EDS results with $\mathrm{Tb}$ peak.

a)

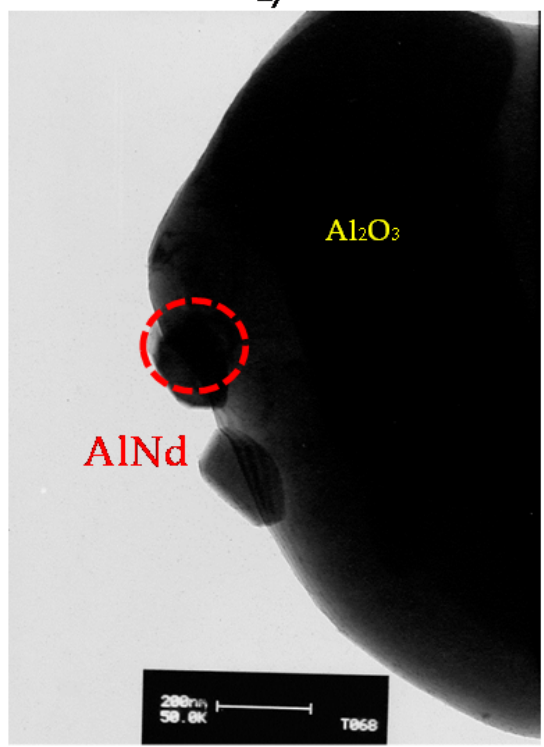

b)

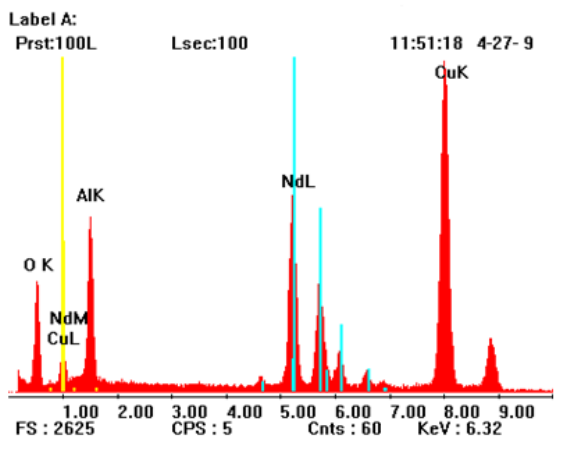

Figure 10. a) TEM image from $\mathrm{Nd}$ doped $\mathrm{Al}_{2} \mathrm{O}_{3}, \mathrm{~b}$ ) EDS results with $\mathrm{Nd}$ peak. 
Figure 11a) shows an example of TEM images obtained for $\alpha-\mathrm{Al}_{2} \mathrm{O}_{3}$ doped with $1 \mathrm{~mol} \%$ of Er and $2 \mathrm{~mol} \%$ of $\mathrm{Yb}$, and calcinated at $1200{ }^{\circ} \mathrm{C}$. EDS analysis show the presence of Er and $\mathrm{Yb}$ dopants in the $\alpha-\mathrm{Al}_{2} \mathrm{O}_{3}$. Electron diffraction analysis identified the crystal as $\mathrm{Yb}_{2} \mathrm{O}_{3}$, however by XRD analysis showed plus two new composition in the samples doped and attributed to $\mathrm{Er}_{2} \mathrm{O}_{3}$ and $\mathrm{Yb}_{3} \mathrm{Al}_{5} \mathrm{O}_{12}$ (Figure 1e). The results of TEM analysis give the following average nanocrystals diameters $\mathrm{D}=(36 \pm 2) \mathrm{nm}$ for the sample calcinated at $1200{ }^{\circ} \mathrm{C}$ and $\mathrm{D}=(182 \pm 8)$ $\mathrm{nm}$ for sample calcinated at $1600{ }^{\circ} \mathrm{C}$ (Figures $9 \mathrm{~d}$ ), these results and the homogeneity in the crystalline size suggests that the nanocrystal powder growth is depending on thermal treatment temperature. The growth and cluster formations of the nanocrystals are the consequence of the reduction of grain boundary area and therefore the total energy of the system.

In the case of $\mathrm{Mg}$ doped alumina there is a formation of $\mathrm{Mg}$ spinel (magnesium aluminate) nanocrystals dispersed on the surface of alumina grains, with size about $40 \mathrm{~nm}$ (Figure 12). It is considered that the high temperature calcination makes magnesium atoms to diffuse to the surface of the clusters, creating a thin layer of magnesium spinel, due to the high local concentration of the dopant.

a)

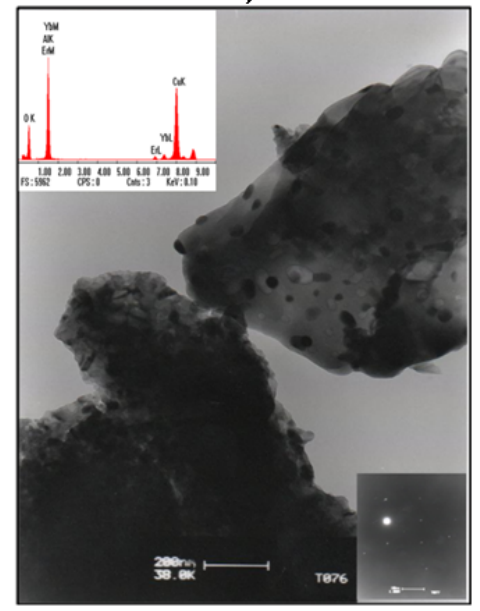

b)

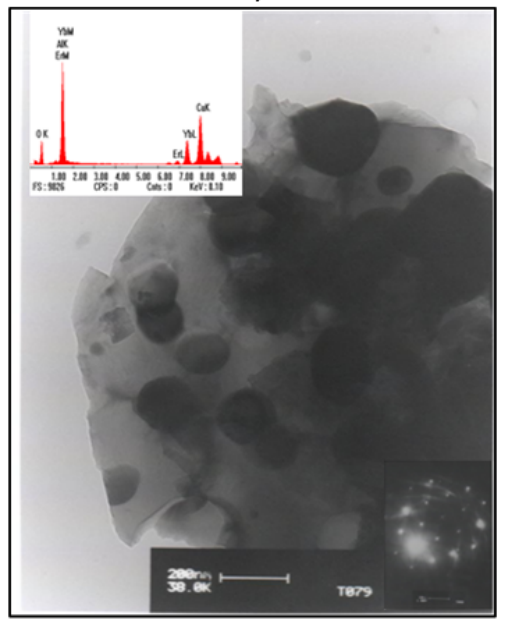

Figure 11. Results of TEM, EDS and Electron diffraction analysis obtained for for $\alpha-\mathrm{Al}_{2} \mathrm{O}_{3}$ doped with 1 $\mathrm{mol} \%$ of $E r$ and $2 \mathrm{~mol} \%$ of $Y b$, and calcinated at $1200^{\circ} \mathrm{C}$ and $1600^{\circ} \mathrm{C}$, (a) TEM images sample calcinated at $1200^{\circ} \mathrm{C},(b) \mathrm{TEM}$ images sample calcinated at $1600^{\circ} \mathrm{C}$. 


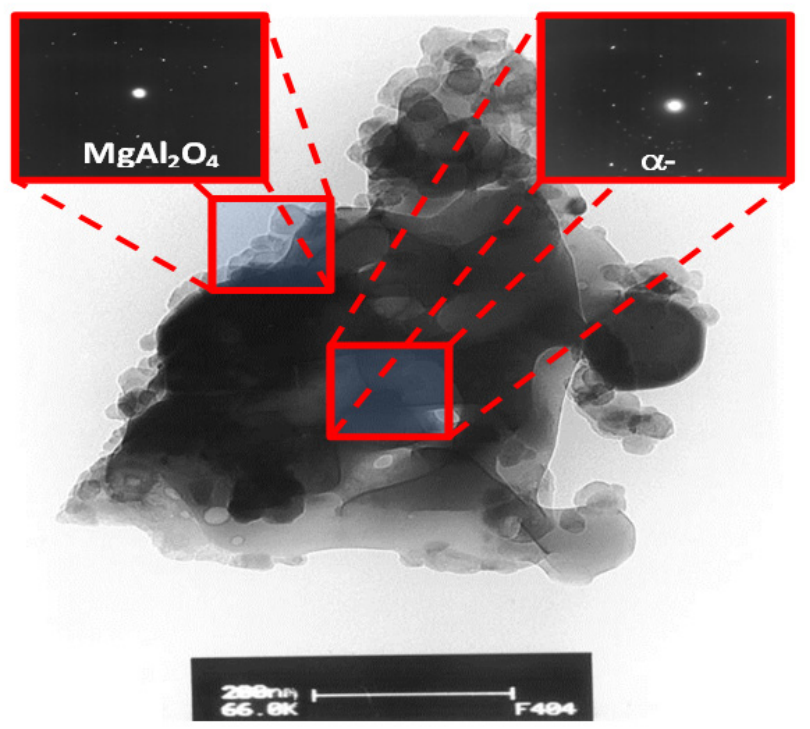

Figure 12. TEM image from magnesium doped $\mathrm{Al}_{2} \mathrm{O}_{3}$. It is considered that the high temperature annealing makes magnesium atoms to diffuse to the surface of the clusters, creating a thin layer of magnesium spinel.

\section{Conclusions}

Polycrystalline powder of $\alpha-\mathrm{Al}_{2} \mathrm{O}_{3}$ was successfully obtained using sol-gel and Pechini process. A second phase was found in doped samples, forming nanocrystals of aluminates and lanthanides oxides on the surface of alumina grains. We did not observe the incorporations of the dopants inside the alumina structure. Strongly dependent of temperature calcinations, the nanocrystallinity of the sample was retained after calcinations at higher temperatures, and an increase in the crystallite size was already perceptible.

The average diameter of nanocrystals depended on the dopant specie: for $\mathrm{Yb}$ and Er doped samples, it was $\mathrm{D}=(36 \pm 2) \mathrm{nm}$ for the sample calcinated at $1200{ }^{\circ} \mathrm{C}$ and $\mathrm{D}=(182 \pm 8) \mathrm{nm}$ for one calcinated at $1600{ }^{\circ} \mathrm{C}$, therefore increased by 5 times. The approximately size of the AlNd is $200 \mathrm{~nm}$ for sample calcinated at $1600{ }^{\circ} \mathrm{C}$ during $4 \mathrm{~h}$ and for $\mathrm{Tb}_{3} \mathrm{Al}_{5} \mathrm{O}_{12}$ crystals the size is about $300 \mathrm{~nm}$ in the same calcination conditions.

The TL emission mechanism in the visible region can be related to $\mathrm{F}$ center and to the lanthanide ( $\mathrm{Ln})$ relaxation. During the irradiation the $\mathrm{Ln}^{3+}$ ion is reduced to $\mathrm{Ln}^{2+}$. It is not completely known if the reduction is due to the transfer of an electron or a hole; however, the process of reduction of trivalent lanthanide ions by irradiation was previously verified in literature $[18,19]$. During thermal stimulation an electron can recombine with the $\mathrm{Ln}^{2+}$ forming $\mathrm{Ln}^{3+^{*}}$ in excited state, which emits a photons returning on this way to the ground state. In the case of $\mathrm{Mg}$ spinel, probably the $\mathrm{Mg}$ ions promoted the oxygen vacancies 
stabilization, improving the luminescence response in the visible spectra, causing the main peak to increase 5 times in comparison with the undoped sample. It is believed that the occurrence of the nanometric spinel layer created an interface between both materials $\left(\mathrm{Al}_{2} \mathrm{O}_{3} / \mathrm{MgAl}_{2} \mathrm{O}_{4}\right)$ with high concentration of defects.

OSL shinedown curves, supplied by undoped samples calcinated to 1200 and $1600{ }^{\circ} \mathrm{C}$, could be fitted by second for all the samples except to $\alpha-\mathrm{Al}_{2} \mathrm{O}_{3}: \mathrm{Yb}, \mathrm{Er}$, which was fitted by first order exponential decay. TL intensity of $190{ }^{\circ} \mathrm{C}$ peak and OSL responses with the dose increased linear for low doses region, from 80 to $1000 \mathrm{mGy}$, and the minimum dose detected value was $5 \mathrm{mGy}$ obtained for TL (UV) and $350 \mu \mathrm{Gy}$ for OSL $\alpha-\mathrm{Al}_{2} \mathrm{O}_{3}+\mathrm{Tb}_{3} \mathrm{Al}_{5} \mathrm{O}_{12}$.

In summary, calcination conditions are of great importance for materials production that are being used as radiation sensors, once it greatly influences the stabilization of intrinsic defects, diffusion of dopants and the occurrence of new phases, due to the incorporation of dopants alongside the matrix, and others. These new phases also seem to play an important role in the luminescence emissions, due to the creation of new trapping and recombination centers, producing materials with unique properties that can be exploited to obtain better dosimeters.

\section{Author details}

Sonia Hatsue Tatumi *, Alexandre Ventieri, José Francisco Sousa Bitencourt, Katia Alessandra Gonçalves, Juan Carlos Ramirez Mittani, René Rojas Rocca and Shiva do Valle Camargo Universidade Federal de São Paulo, Universidade de São Paulo, Centro Estadual de Educação Tecnológica Paula Souza, Brazil

\section{Acknowledgement}

The authors wish to thanks to FAPESP, CAPES and CNPq for financial support.

\section{References}

[1] Aitken MJ (1985) Thermoluminescence Dating. Academic Press. 3 p.

[2] Becquerel AH (1883) Maxima et Minima d'excitinction de al Phosphorescence sous l'Influence des Radiations Infra-rouge. Comptes Rendus 96: 1853-1856.

[3] Randall JT, Wilkins MHF (1945) Phosphorescence and Electron Traps. I. The study of Trap Distributions. Proc. Royal Soc. Lond. 184: 366-389.

[4] McKeever SWS (1985) Thermoluminescence of Solids. Cambridge University Press. 8 p.

[5] Cameron JR, Suntharalingam N, Kenney GN (1968) Thermoluminescent Dosimetry. University of Wisconsin Press.

\footnotetext{
${ }^{*}$ Corresponding Author
} 
[6] Akselrod MS, Kortov VS, Kravetsky DJ, Gotlib VI (1990) High Sensitive Thermoluminescent Anion-Defect $\alpha-\mathrm{Al}_{2} \mathrm{O}_{3}$ : C Single Crystal Detectors. Radiat. Prot. Dosim. 33: 119-122.

[7] Halperin A, Kristianpoller N, Ben-Zvi A (1959) Thermoluminescence of X-Ray Colored $\mathrm{NaCl}$ Crystals. Phys. Rev. 116: 1081-1089.

[8] Mehendru PC (1970) Effects of Heat Treatment and Background Divalent Cation Impurity on the Growth of F Centers in Highly Pure KCl Crystals. Phys. Rev. B 1: 809814.

[9] Kitis G, Charitidis C, Charalambous S (1990) Thermoluminescence Sensitization of LiF: $\mathrm{Mg}$, Ti Under Heat Treatment Between 150 and $400{ }^{\circ} \mathrm{C}$. Nuclear Instruments and Methods in Physics Research Section B: Beam Interactions with Materials and Atoms 51, 3: 263-268.

[10] Piters TM, Bos AJJ, Van der Burg B (1996) Effects of Annealing on Glow Peak Paramenters of LiF: Mg, Ti (TLD-100) Dosimetry Material. Radiat. Prot. Dosim. 84, 1-4: 201-206.

[11] Bhatt BC, Menon SN, Mitra R (1999) Effects of Pre- and Post-Irradiation Temperature Treatments on TL Characteristics and Radiation Induced Sensitisation of Various TL Peaks in LiF (TLD-100). Radiat. Prot. Dosim. 84, 1-4: 175-178.

[12] Holgate SA, Sloane TH, Townsend PD, White DR, Chadwick AV (1994) Thermoluminescence of Calcium Fluoride doped with Neodymium. Journal of Physics: Condensed Matter 6: 9255-9266.

[13] Huntley DJ, Godfrey-Smith DI, Thewalt MLW (1985) Optical Dating of Sediments: Nature 313: 105-107.

[14] Antonov-Romanovsky VV, Keirum-Markus IF, Poroshina MS, Trapeznikova ZA (1956) IR Stimulable Phosphors. Conference of Academy of Sciences of the USSR on the peaceful uses of Atomic energy. USAEC Report AEC-tr-2435 Pt.1: 239-250.

[15] Bräunlich P, Schaffer D, Scharmann A (1967) A Simple Model for Thermoluminescence and Thermally Stimulated Conductivity of Inorganic Photoconducting Phosphors and Experiments Pertaining to Infra-Red Stimulated Luminescence. Luminescence Dosimetry: 57- 63.

[16] Sanborn EN, Beard EL (1967) Sulfides of Strontium, Calcium and Magnesium in Infrared-Stimulated Luminescence Dosimetry. Luminescence Dosimetry: 183-193.

[17] Nanto H, Murayama K, Usuda T, Taniguchi S, Takeuchi N (1993) Optically Stimulated Luminescence in KCl: Eu Single Crystal. Radiat. Prot. Dosim. 47: 281-284.

[18] Akselrod MS, Lucas AC, Polf JC, McKeever SWS (1998) Optically Stimulated Luminescence of $\mathrm{Al}_{2} \mathrm{O}_{3}$. Radiat. Meas. 29: 391-399.

[19] McKeever SWS, Akselrod MS (1999) Radiation Dosimetry Using Pulsed Optically Stimulated Luminescence of $\mathrm{Al}_{2} \mathrm{O}_{3}$ : C. Radiat. Prot. Dosim. 84: 317-320.

[20] McKeever SWS (2001) Optically Stimulated Luminescence Dosimetry. Nucl. Instr. Meth. Phys. Res. B 184: 29-54. 
[21] Yukihara EG, McKeever SWS (2006) Spectroscopy and Optically Stimulated Luminescence of $\mathrm{Al}_{2} \mathrm{O}_{3}$ : C using Time-Resolved Measurements. J. Appl. Phys. 100,083512 (9 pages).

[22] Itou M, Fujiwara A, Uchino T (2009) Reversible Photoinduced Interconversion of Color Centers in $\alpha-\mathrm{Al}_{2} \mathrm{O}_{3}$ Prepared under Vacuum. J. Phys. Chem. 113: 20949-20957.

[23] Douguchi Y, Nanto H, Sato T, Imai A, Nasu S, Kusano E, Kinbara A (1999) Optically Stimulated Luminescence in Eu-doped KBr Phosphor Ceramics. Radiat. Prot. Dosim. 84: 143-148.

[24] Gaza R, McKeever SWS (2006) A Real-Time High-Resolution Optical Fibre Dosemeter Based on Optically Stimulated Luminescence (OSL) of KBr: Eu, for potential use during radiotherapy of cancer. Radiat. Prot. Dosim. 120: 14-19.

[25] Mittani JC, Proki'c M, Yukihara EG (2008) Optically Stimulated Luminescence and Thermoluminescence of Terbium-activated Silicates and Aluminates. Radiation Measurements 43: 323-326.

[26] Bitencourt JFS, Tatumi SH (2009) Synthesis and Thermoluminescence Properties of $\mathrm{Mg}^{2+}$ Doped Nanostructured Aluminium Oxide. Physics Procedia 2: 501-514.

[27] Bitencourt JFS, Ventieri A, Gonçalves KA, Pires EL, Mittani JC, Tatumi SH (2010) Comparison Between Neodymium Doped Alumina Samples Obtained by Pechini and Sol-gel Methods using Thermo-Stimulated Luminescence and SEM. Journal of NonCrystalline Solids 356: 2956-2959.

[28] Gonçalves KA, Bitencourt JFS, Mittani JCR, Tatumi SH (2010) Study of Radiation Induced Effects in the Luminescence of Nanostructured $\mathrm{Al}_{2} \mathrm{O}_{3}: \mathrm{Yb}$, Er crystals. IOP Conf. Series: Materials Science and Engineering 15: 012080.

[29] Pires EL, Tatumi SH, Mittani JCR, Caldas LVE (2011) TL and OSL Properties of KAlSi3 8 : Mn Obtained by Sol-gel Process. Radiation Measurements 46: 473-476.

[30] Pires EL, Tatumi SH, Mittani JCR, Kinoshita A, Baffa O, Caldas LVE (2011) TL, OSL and ESR Properties of Nanostructured KAlSi3 $\mathrm{O}_{8}$ : Mn Glass. Radiation Measurements 46: 1492-1495.

[31] Summers GP (1984) Thermoluminescence in single crystal $\alpha-\mathrm{Al}_{2} \mathrm{O}_{3}$ : C. Radiat. Prot. Dosim. 8: 69-80.

[32] Lee KH, Crawford JH (1979) Luminescence of the F Center in Sapphire. Phys. Rev. 19: 3217-3221.

[33] Kristianpoller N, Rehavi A, Shmilevich A, Weiss D, Chen R (1998) Radiation Effects in Pure and Doped $\mathrm{Al}_{2} \mathrm{O}_{3}$ Crystals. Nuclear Instruments and Methods 141: 343-346.

[34] Ropp RC (1991) Luminescence and the Solid State. Elsevier. 401 p.

[35] Jaque D, Capmany J, Luo ZD, Garcia Sole J (1997) Optical Bands and Energy Levels of $\mathrm{Nd}^{3+}$ Ion in the $\mathrm{YAl}_{3}\left(\mathrm{BO}_{3}\right)_{4}$ Non-linear Laser Crystal. J. Phys: Condens. Matter 9: 97159729.

[36] McKeever SWS, Chen R (1997) Luminescence Models Radiation Measurements 27 5/6: 625-661. 
[37] Yang X, Li H, Bi Q, Cheng Y, Tang Q, Su L, Xu J (2008) Growth of Highly Sensitive Thermoluminescent Crystal $\alpha-\mathrm{Al}_{2} \mathrm{O}_{3}$ : $\mathrm{C}$ by the Temperature Gradient Technique. Journal of Crystal Growth 310: 3800-3803. 